\title{
CONTROL DE CONVENCIONALIDAD
}

\author{
Sergio GARCÍA RAMÍREZ
}

En estos años ha cobrado gran importancia y visibilidad entre los temas de la protección internacional de los derechos humanos - especialmente en el medio interamericano- el denominado "control de convencionalidad", sobre el que se ha pronunciado la Corte Interamericana en numerosas ocasiones, que se ha recogido en la jurisprudencia de varios Estados de la región y que cuenta en su haber con nutrida y creciente bibliografía.

Hace algunos lustros me referí a esta cuestión, de manera incipiente, en el comentario sobre una apreciable obra colectiva de Derecho procesal constitucional. Entonces aludí a un "control de internacionalidad", que andando el tiempo devendría, doctrinaria y jurisprudencialmente, "control de convencionalidad", paralelo al "control de constitucionalidad". Entonces mencioné las fuentes de aquel control.

El auge de esta figura se conecta tanto con la vocación institucional de la Corte Interamericana, un tribunal llamado a dictar resoluciones "trascendentes" - tema al que he aludido reiteradamente-, que concurran a la relectura o reelaboración del aparato jurídico nacional $\mathrm{y}$, a la postre, del internacional, por la vía del ius commune interamericano, como con la nueva prestancia adquirida por el órgano jurisdiccional, en su doble dimensión: doméstico o interno y supranacional (o internacional).

Por lo que toca a la conexión del control de convencionalidad con lo que antes llamé la nueva prestancia del órgano jurisdiccional, cabe decir que éste había permanecido un tanto en la sombra - si se me permite la expresión - y que ahora, lejos de ser la "boca que pronuncia las palabras de la ley" (en términos de Montesquieu, plenamente justificados al calor de la demolición del absolutismo y elevación de la voluntad general acogida en el Parlamento) concurre a las grandes definiciones nacionales con insólita pujanza, al punto que parece haber "destronado al legislador". Esta nueva prestancia del juzgador no debiera conducir, sin embargo, a una dictadura judicial o a un gobierno de los jueces, que pudiera derivar del hiperactivismo sin fronteras ni controles. No pretendo ir ahora más lejos en el examen de esta sociedad entre la majestad del juzgador y el desarrollo del control de convencionalidad.

Se ha dicho que el control de convencionalidad constituye "una garantía destinada a obtener la aplicación armónica del derecho vigente", concepto que para ese fin abarca normas de ambas fuentes utilizables: internacional y nacional, bajo la "guía" de aquélla. Parece obvio que la Corte Interamericana, que conoce de actos nacionales violatorios de normas internacionales, debe ejercer un control de aquéllos a la luz de su congruencia con los mandamientos convencionales. Se trata de llevar a cabo el cotejo, la confrontación, la comparación

\footnotetext{
${ }^{1}$ Investigador en el Instituto de Investigaciones Jurídicas de la Universidad Nacional Autónoma de México. Investigador Nacional Emérito del Sistema Nacional de Investigadores (México).Expresidente de la Corte Interamericana de Derechos Humanos.
} 
entre unos y otros - destacando la prevalencia de la norma convencional- materia para el análisis del Tribunal y razón de sus determinaciones.

Debo manifestar desde ahora que el control de convencionalidad (deber que recae en el universo de obligados al que aludiré infra, asunto que, por lo demás, no se halla completamente definido) no se confunde con la obligación general de observancia o subordinación a las disposiciones del DIDH (deber a cargo de todas las autoridades públicas, como lo señala, por ejemplo, el artículo $1^{\circ}$ de la Constitución mexicana, a partir de la reforma de 2011 , e incluso de los particulares). Esta observancia o subordinación corresponde al deber que cada quien tiene con respecto a su propia conducta: conducirse, personalmente, en los términos establecidos por las disposiciones jurídicas. En cambio, la obligación de control se ejerce en relación con un tercero, el "sujeto controlado", cuyos actos examina el "sujeto controlador" para verificar la conformidad entre esos actos y los mandamientos del DIDH (o el Derecho nacional de los derechos humanos) y aplicar, a tal efecto, determinadas medidas con ciertas consecuencias, a las que adelante me referiré.

Se advierte que la misión del Tribunal internacional como "sujeto controlador" se asemeja, en ciertos rasgos esenciales, a la de un Tribunal constitucional interno, llamado a pronunciarse sobre la "calidad constitucional" del acto de una autoridad doméstica, tomando como punto de referencia el texto de la norma suprema interna y la interpretación que en torno a ella formule el órgano de constitucionalidad.

A partir del primer enunciado del control de convencionalidad, inicialmente en votos particulares y poco después, evolutivamente, en jurisprudencia de la Corte en pleno, esta figura adquirió prestigio y desarrollo. La CorteIDH ha formulado definiciones y precisiones acerca del control de convencionalidad, que han significado una evolución importante a este respecto. Sin embargo, aún no existe en todos los países de nuestra región un concepto unánimemente aceptado acerca de dicho control, el procedimiento o método para ejercerlo y sus consecuencias; tampoco lo hay en torno a los sujetos facultados para aplicarlo y a las hipótesis en las que se debe aplicar. Por ello, lo que digo ahora debe ser tomado con reserva, considerando las particularidades de cada régimen nacional e incluso de cada analista o aplicador del nuevo control. Hay una extensa variedad de soluciones y opiniones, que por sí misma acredita - es obvio - la necesidad de llevar a cabo un pulcro reexamen de esta figura garantista, animada por vientos de diversa naturaleza y conducida con distinto - e incierto- destino.

Es deseable llegar pronto a coincidencias básicas en torno a las cuestiones que suscita el control de convencionalidad, a menudo fomentadas por el "entusiasmo" y las crecientes expectativas. Las coincidencias básicas permitirán que el control de convencionalidad alcance las mejores aplicaciones de que seamos capaces, adquiera razonable uniformidad en nuestra región y contribuya a la formación del ius commune, a la armonización y congruencia, a la definición plausible y admisible del orden jurídico y de sus garantías. Si esto no sucede, el riesgo es que se alimente la dispersión, surjan contradicciones en el interior de los países —no sólo de los países entre sí- y decaiga la tutela continental de los derechos humanos.

Desde luego, es la propia Corte Interamericana la instancia autorizada para resolver, en definitiva, si se ha ejercido rectamente el control de convencionalidad con respecto al siste- 
ma interamericano, toda vez que no existe órgano superior calificado para revisar las decisiones de aquel Tribunal.

Hay etapas o "tiempos" en el desarrollo jurisprudencial interamericano sobre el control. En los siguientes párrafos me referiré a las novedades características de cada etapa, indicando también el caso que las aportó, en la inteligencia de que los nuevos términos establecidos en dicho caso se han reiterado en la jurisprudencia subsecuente. En lo que toca al Caso Gelman, haré la precisión pertinente en el lugar adecuado.

Con apoyo en la idea de que la función garantizadora del Estado - y la consecuente responsabilidad - abarca a todos los órganos de éste, se entendió que los juzgadores internos se hallan comprometidos a respetar y garantizar la observancia del DIDH, y que en este sentido su función natural - jurisdiccional— debía servir a aquellos fines y salir al paso de violaciones en normas jurídicas internas. Para ello, deben ejercer una especie de control de convencionalidad (Caso Almonacid vs Chile), expresión que coincide literalmente con la que utilicé en mi voto para el caso Mack Chang, al que me referí supra..

Esta misión judicial de garante de los derechos humanos — sustentada en las Constituciones internas y en el DIDH - no sólo posee eficacia represiva, sino valor preventivo, en el sentido de que "depura" la actuación del Estado y limita el desempeño del tribunal internacional, que tendría una actuación menos frecuente, en virtud de que se ve acotada por el principio de subsidiariedad. En contraste, todo aquello que no resulte eficazmente controlado por el juzgador nacional —o por otras instancias internas competentes- podrá ser objeto de planteamiento y examen por el tribunal internacional.

Así, pues, la Corte Interamericana entendió que el control de convencionalidad al que se refería esta doctrina emergente, sería ejercido por los juzgadores nacionales, a la manera en que la CorteIDH, controladora natural de la convencionalidad, ejerce esta función en el ámbito internacional. El control doméstico quedaba en manos, pues, de los órganos jurisdiccionales, convocados a la tutela interna, que para ello atenderían al Derecho internacional. Parecía razonable que así fuera.

Posteriormente se agregó que los tribunales ejercerían el control conforme a su propia competencia y dentro de los procedimientos establecidos para ello, previsión adecuada en términos prácticos e incuestionable en términos jurídicos, atenta al régimen de legalidad que preside el desempeño de los tribunales y, en general, de todas las autoridades. Esta misión se ejercería por el juzgador motu proprio, en el mismo desempeño del principio iura novit curia que preside el quehacer general de la Corte, y no dependería de la instancia de los interesados. Dicha función "no debe quedar limitada exclusivamente por las manifestaciones o actos de los accionantes en cada caso concreto, aunque tampoco implica que ese control deba ejercerse siempre, sin considerar otros presupuestos formales y materiales de admisibilidad y procedencia de ese tipo de acciones" (Caso Trabajadores Cesados del Congreso vs. Perú).

Vale decir que el alcance de esta última expresión no fue aclarado por la jurisprudencia de la Corte. Doctrinalmente se ha llamado la atención en torno a esos términos, que reconoce la pertinencia de atender a ciertas condiciones materiales y formales para la apertura, en sus casos, de los controles internacional y nacional.

Poco después de emitidas las sentencias primordiales, se creyó conveniente extender el ejercicio del control a otras autoridades: "órganos vinculados a la administración de justicia en todos los niveles" (Caso García y Montiel Flores vs. México). Pero es preciso tomar en cuenta que tales órganos vinculados a la administración de justicia en todos sus niveles 
constituyen un universo muy amplio en el que figuran funcionarios públicos con diversas atribuciones primarias y preparación profesional: no solamente secretarios judiciales, entre cuyas funciones se halla la suplencia de los juzgadores (es decir, el ejercicio de la jurisdicción), sino también personas con otra misión natural.

Un paso más allá se encuentra la encomienda de control que se asigna a todos los servidores públicos (Caso Gelman vs. Uruguay). Ciertamente, éstos se hallan obligados a cumplir las disposiciones de la Constitución interna y de los tratados internacionales. Ahora bien, una cosa es este deber general de cumplimiento, que no hace excepciones, y otra la misión de "control" de los actos de otras autoridades. Líneas abajo me referiré al alcance que este control puede poseer.

Al ampliarse de tal suerte el catálogo de los "controladores" - que no es sinónimo de los obligados a la observancia de normas nacionales e internacionales-, se invistió automáticamente con la misión de control a servidores públicos de todos los rangos, especialidades, competencias: desde miembros de la fuerza pública, hasta docentes y funcionarios de salud, desde empleados del servicio postal hasta operarios de órganos de la Administración Pública central y descentralizada, y así sucesivamente. No deja lugar a dudas sobre esta amplísima consecuencia la literalidad de las expresiones utilizadas para establecer la encomienda de control. Si se quiere "racionalizarla", asignándole determinadas fronteras, habría que echar mano de elaboradas interpretaciones o de francas y acaso pertinentes aclaraciones y rectificaciones.

Es interesante observar que la doctrina acogida por el Tribunal Interamericano en sus pronunciamientos primordiales fue invocada de nueva cuenta por el presidente de aquél, en oportunidad del período extraordinario de sesiones de la Corte, realizado en la ciudad de México en diciembre de 2013. Sugería una cautela que favoreciera el sano desenvolvimiento del control: desenvolvimiento y encauzamiento para evitar que esta figura jurídica saliera de su cauce.

Como se ha visto, la idea del control de convencionalidad se refirió a la intervención "judicial" nacional en el examen de "normas domésticas". Esto asigna al control un perfil estricto. En cambio, si se considera que aquella denominación corresponde al examen de "cualquier acto violatorio" por parte de "cualquier autoridad" interna, el control adquiere una extensión ilimitada: todos los exámenes de congruencia entre un acto interno y una norma del DIDH constituirían control de convencionalidad.

Veamos ahora cómo se podría ejercer este control y cuáles serían sus consecuencias jurídicas. La Corte Interamericana no ordenó un régimen de control difuso, aunque probablemente simpatizara con él. Dejó la decisión final a cargo de los Estados, a condición de que aquélla favoreciera el control judicial de convencionalidad, eje del sistema propuesto. Así las cosas, parecía perfectamente posible - y pertinente- revisar las circunstancias en las que operaría el control y adoptar los mejores términos a la luz de aquéllas.

Desde que emprendí el estudio del control de convencionalidad en México, subrayé que la Corte Interamericana no se ha pronunciado sobre la naturaleza de ese control: concentrado o difuso. Es indispensable, a mi juicio, ponderar con cuidadosa reflexión la vía más conveniente para hacer del control un instrumento de armonización jurídica, seguridad y justicia, ruta hacia el ius commune, no hacia la dispersión jurisprudencial, que constituye uno de los más graves riesgos en este ámbito. En este orden de consideraciones "es perfectamente posible - añadí- que el legislador interno organice un régimen de consultas similar a las 
cuestiones de constitucionalidad que ofrecen otras experiencias nacionales y que permiten la unidad de interpretación y favorecen la seguridad jurídica”.

En sentido similar se han pronunciado diversos tratadistas, preocupados por los efectos de una ausencia casi total de regulación, así como por los problemas que puede suscitar la divergencia de opiniones entre tribunales que ejercen control, con el consiguiente quebranto del principio de seguridad jurídica que constituye un elemento fundamental del Estado de Derecho. Se ha sugerido, inclusive, la incorporación de una solución de media vía entre el control difuso absoluto y el control concentrado, tomando nota de regímenes aprovechables para este fin, como las cuestiones de constitucionalidad del Derecho español.

Al referirse a la que denomina aceptación tácita calificada de los pronunciamientos de la CorteIDH por los tribunales nacionales, un tratadista señala que los jueces inferiores generalmente no practican tal control (de convencionalidad) aunque elevan el caso vía consulta de constitucionalidad, a la Sala Constitucional. Hay quienes ven en ello un beneficio, a fin de evitar interpretaciones divergentes por parte de tales jueces y sentar criterios uniformes mediante la jurisprudencia de la aludida Sala.

No sobra recordar que algunos países de la región tienen tradición de control difuso; otros, de control concentrado con profunda raíz y buen funcionamiento en general. Tampoco sobra observar que en algunos Estados el número de juzgadores es relativamente reducido, al paso que en otros es sumamente amplio y corresponde a múltiples especialidades: piénsese en millares - no apenas decenas o centenares - de juzgadores, sin antecedentes, ni cercanos ni remotos, en materia de control difuso, ejerciendo éste sobre muy distintas materias, en sus respectivas trincheras: civiles, penales, familiares, mercantiles, de garantías, administrativos, agrarios, de justicia cívica (o menor o de paz, municipal), laborales, etcétera.

Mencioné que cada país puede ofrecer particularidades en lo que respecta a los efectos inmediatos del control de convencionalidad, así como en lo que toca a los problemas que pueden enfrentar los jueces para aplicar el control, sobre todo si éste se establece en forma súbita, sin suficiente preparación para aplicar el control o nuevas disposiciones de protección de derechos humanos, que implican cambios de importancia mayor.

No me es posible aludir a todos los países, pero puedo proponer el ejemplo de México. Si nos referimos al examen de disposiciones de general alcance - leyes y reglamentos, que fueron la materia que promovió las primeras apariciones en la escena de la figura que ahora examinamos-, control de convencionalidad significa "inaplicación" de una norma o "expulsión” de ésta del ordenamiento interno, en diferentes supuestos. ¿Cómo resolver los problemas que generaría la "multiplicación de inaplicaciones y expulsiones", si no se cuenta con legislación a la mano, que brinde seguridad y propicie justicia?

Es relevante mencionar una incipiente práctica que aparece en el empleo del control de convencionalidad como medio para impulsar, con deliberación estratégica, el favorecimiento de derechos humanos en determinados espacios. Esto puede operar con especial énfasis cuando vienen al caso integrantes de grupos vulnerables a los que la magistratura se esfuerza en extender los beneficios de la equidad.

La idea de aplicación directa de normas y sentencias internacionales por parte de tribunales domésticos no es extraña, por cierto, para el sistema jurisdiccional europeo de protección de los derechos humanos. Bajo un "principio de solidaridad", la Corte Europea vería aplicados sus pronunciamientos en Estados que no figuraron como litigantes en el caso en que se produjo el pronunciamiento ante esa jurisdicción. La Corte Europea hace notar "que si bien la existencia de un recurso es necesaria, no es suficiente: falta aún que las jurisdicciones 
nacionales tengan la posibilidad en el derecho interno de aplicar directamente la jurisprudencia europea y que el conocimiento de esta jurisprudencia sea facilitado por los Estados".

A todo esto, que atañe a la recepción interna del Derecho internacional de los derechos humanos y al diálogo jurisdiccional - mejor que jurisprudencial- entre tribunales, bajo el concepto de cross fertilization, es preciso agregar la novedosa posibilidad, alojada en el proyecto de protocolo16 al Convenio Europeo, de que los altos tribunales de un Estado parte soliciten opiniones consultivas a la Corte Europea. Como se sabe, las atribuciones consultivas de este tribunal son muy reducidas, pero crecerían notablemente si se acogiese dicho instrumento - al que también se califica como "protocolo del diálogo" - y se permitiera que un órgano jurisdiccional interno formulase a la Corte Europea consulta acerca de cuestiones convencionales que se suscitan en el marco de un caso sujeto al conocimiento jurisdiccional del solicitante. No iré más lejos en la referencia a este punto, que amerita comentario detallado. 